Original Article

\title{
The Presence of Patent Foramen Ovale in the Superior Type of Sinus Venosus Atrial Septal Defect
}

\author{
Niloufar Samiei, MD ${ }^{1}$, Nehzat Akiash, MD²*, Sepideh Djafari Naeini, MD³, \\ Akbar Nikpajouh, MD, MPH${ }^{1}$, Mahboubeh Pazoki, MD ${ }^{4}$
}

\footnotetext{
${ }^{1}$ Heart Valve Disease Research Center, Rajaie Cardiovascular Medical and Research Center, Iran

University of Medical Sciences, Tehran, Iran.

${ }^{2}$ Atherosclerosis Research Center, Ahvaz Jundishapur University of Medical Sciences, Ahvaz, Iran.

${ }^{3}$ Cardiovascular Research Center, Shahid Beheshti University of Medical Sciences, Tehran, Iran.

${ }^{4}$ Rasul Akram General Hospital, Iran University of Medical Sciences, Tehran, Iran.
}

\section{Abstract}

Background: The superior type of sinus venosus atrial septal defect (SVASD) is a rare form of the atrial septal defect (ASD) in which the upper part of the atrial septum does not exist. The presence of other cardiac anomalies such as anomalous pulmonary venous connections has been reported in this type of congenital heart disease. This study aimed to assess the presence of the patent foramen ovale (PFO) in patients with the superior type of SVASD.

Methods: This retrospective case-control study on 387 patients, consisting of 187 patients with a definite SVASD and 200 patients with problems other than the ASD, was conducted in Rajaie Cardiovascular Medical and Research Center between February 2005 and July 2014. Seven patients with inadequate data were excluded from the analysis. The presencelabsence of the PFO was also evaluated in the case and control groups.

Results: The analyses were performed on 182 male and 198 female patients at a mean age of $39.07 \pm 14.41$ and $51.01 \pm 15.80$ years in the case and control groups, respectively. The PFO was significantly more frequent in the patients with the superior type of SVASD than in those without the condition $(P<0.001)$. The persistence of the left superior vena cava was seen in 34 out of 180 patients with SVASD and in 1 out of 200 patients without the condition (18.9\% vs $0.5 \%$; $P<0.001$ ).

Conclusion: This study was the first to highlight the coexistence of the PFO and the superior type of SVASD. Physiological, genetic, or fetal factors may play an important role in the association between the PFO and the SVASD.

\section{J Teh Univ Heart Ctr 2020;15(3):98-104}

This paper should be cited as: Samiei N, Akiash N, Djafari Naeini S, Nikpajouh A, Pazoki M. The Presence of Patent Foramen Ovale in the Superior Type of Sinus Venosus Atrial Septal Defect. J Teh Univ Heart Ctr 2020;15(3):98-104.

Keywords: Foramen ovale, patent; Atrial septal defect sinus venosus; Echocardiography, transesophageal

\section{Introduction}

The patent foramen ovale (PFO) is commonly considered a normal anatomic variant. During the early development, the septum primum divides the common atrium into left and right atria and remains an opening that is called the "ostium primum". As the size of the ostium primum decreases, the ostium secundum is formed in the

"Corresponding Author: Nehzat Akiash, Assistant Professor of Cardiology, Imam Khomeini Hospital, Azadegan Street, Ahvaz, Iran. 6193673166. Tel: +98 61 32228037.Fax: +982189779503.E-mail: akiash.n@gmail.com

98 
septum primum. The septum secundum grows at the right side of the septum primum and covers the majority of the ostium secundum and finally, the residual foramen is the foramen ovale. ${ }^{1}$ The PFO is a potential source of embolism and cryptogenic stroke in young adults. ${ }^{2,3}$ During the fetal life, when the lungs cannot receive the blood flow, the blood entering the right atrium flows directly into the left atrium via the PFO. ${ }^{4,5}$ After birth, the foramen ovale fails to close and results in a left-to-right shunt in approximately $25 \%$ of the population. ${ }^{6,7}$ Contrast echocardiography with agitated saline is a useful method for a precise evaluation of the PFO. The Valsalva maneuver during contrast injection may have a clinical value for the evaluation of the PFO in patients suspected of paradoxical emboli. ${ }^{8}$

The atrial septal defect (ASD) is a deficiency in the interatrial septum. The condition is categorized as the ostium secundum ASD, the ostium primum ASD, and the sinus venosus atrial septal defect (SVASD). The ostium secundum ASD is a true defect of the atrial septum which involves the fossa ovalis. The ostium primum ASD is classified as an atrioventricular septal defect. In superior vena cava (SVC) type of SVASD, a defect usually occurs at the junction of the SVC and the right atrium. There are 2 rare types of ASDs: the inferior vena cava (IVC) type of SVASD and the unroofed coronary sinus. ${ }^{9}$

In the superior type of SVASD, which accounts for $4 \%$ to $11 \%$ of all ASDs, the upper part of the atrial septum, the SVC, and the right-sided pulmonary veins do not exist. ${ }^{10}$ In this type of disorder, an overriding SVC is seen on the atrial septum. The partial anomalous pulmonary venous connection (PAPVC) in some pulmonary veins, especially the abnormal drainage of the right pulmonary veins, is associated with the SVC type of SVASD. ${ }^{11}$ The diagnosis of this type of ASD is more difficult than other types of ASDs and sometimes requires other diagnostic methods such as transesophageal echocardiography (TEE), cardiac magnetic resonance imaging, ${ }^{12,13}$ and multidetector computed tomography. ${ }^{14,15}$

The purpose of this study was to investigate the coexistence of the PFO and the superior type of SVASD. As is known, patients with the SVASD require surgery for the correction of the cardiac anomalies. As a result, all abnormalities associated with the SVASD such as the PAPVC and the PFO should be diagnosed before surgery.

\section{Methods}

This retrospective case-control study was conducted in Rajaie Cardiovascular Medical and Research Center. The echocardiography reports of the patients that had undergone TEE between February 2005 and July 2014 were reviewed to identify patients with the SVASD. The case group comprised patients with the SVASD, and the control group consisted of patients who had undergone TEE due to problems other than congenital heart diseases. The results were evaluated by 2 readers, and the presence/ absence of the PFO in the TEE reports of the patients with the SVASD was checked. The presence/absence of the PFO was also evaluated in the control group. The required information was obtained from a database maintained in the Echocardiography Ward of Rajaie Cardiovascular Medical and Research Center.

Patients were eligible if TEE confirmed a defect at the connection of the SVC to the right atrium. The presence/ absence of the PAPVC, the PFO, and other congenital heart defects was recorded in all the patients. The patients with unclear reports of TEE (e.g., suspicions for the PAPVC) were excluded from the study.

Baseline transthoracic echocardiography (TTE) and TEE were performed in both the case and control groups. The two investigators assessed the echocardiography reports of the case group to diagnose the SVASD and to determine the presence/absence of the PFO. Echocardiography was once performed by fellows training in clinical echocardiography. The echocardiograms were then reviewed again by the attending physicians of the echocardiography ward with at least 8 years of experience in clinical echocardiography.

Echocardiographic measurements, including the enddiastolic and the end-systolic diameters of the left ventricle, were performed in the parasternal long-axis view. The maximal basal right ventricular diameter was estimated in the apical 4-chamber view during the diastolic phase. The right ventricular systolic function was assessed using the tricuspid annular plane systolic excursion (TAPSE) and the velocity of the tricuspid annular systolic motion $\left(\mathrm{S}^{\prime}\right)$. TAPSE and $\mathrm{S}^{\prime}$ were determined by M-mode and tissue Doppler imaging in the 4-chamber view, respectively. Stenosis and regurgitation in the heart valves were evaluated during echocardiography. In the case group, the presence of the SVASD was proven in the bicaval view via a 2D TEE method (Figure 1A) and a color-flow Doppler study (Figure 1B).

The presence of the PFO in TTE and TEE was first investigated via $2 \mathrm{D}$ echocardiography and the colorflow Doppler study (Figure 2). In the control group, any doubts regarding the presence or absence of the PFO were resolved through multiple saline injections and provocative maneuvers, followed by the tracking of the bubbles crossing the foramen ovale using contrast echocardiography. A PFO was considered to be present if more than 3 contrast bubbles crossed the foramen ovale in TEE. In the case group, due to the coexistence of a defect in the atrial septum, evaluating the passage of a bubble from the right atrium to the left atrium was not sufficient and special focus was placed on the bubble cross-path for a PFO diagnosis. Therefore, the PFO was documented by 2D echocardiography, colorflow Doppler, and contrast injection. The right pulmonary 
veins were evaluated in the mid-esophageal level at $0^{\circ}$ (Figure 3 ) or from $90^{\circ}$ to $110^{\circ}$ in the bicaval view with a clockwise rotation. Both right pulmonary veins were also visualized from the mid-esophageal view at $40^{\circ}$ to $60^{\circ}$ (Figure 4 ). The left pulmonary veins were examined with a counterclockwise rotation of about $90^{\circ}$ to $110^{\circ}$. Furthermore, the left upper pulmonary vein was assessed during the evaluation of the upper part of the left atrial appendage. In some cases with a dilated coronary sinus, the presence of the persistent left SVC was confirmed with visible bubbles in the coronary sinus after intravenous saline injection into the left antecubital vein.

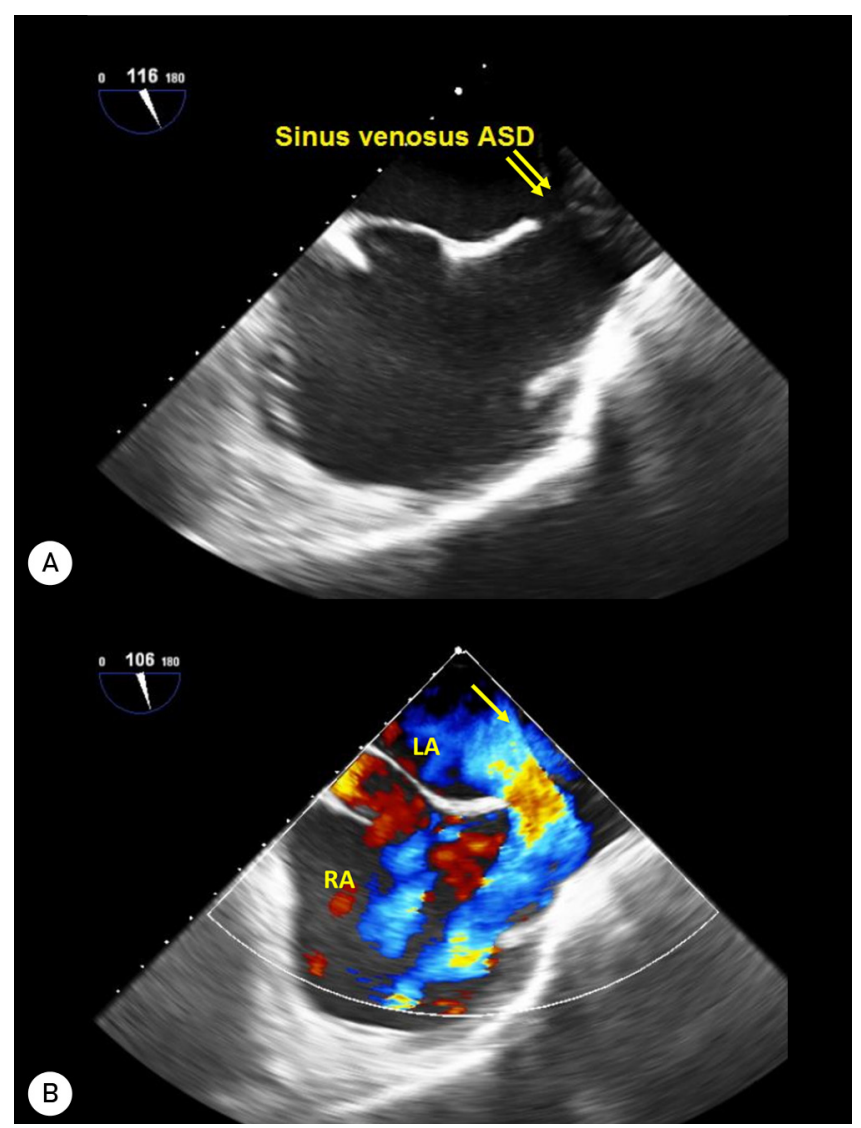

Figure 1. Transesophageal echocardiography, mid-esophageal bicaval views (90-120 $)$, showing the sinus venous ASD with a left- to- right shunt:, A) sinus venous ASD (double arrow) and; B) a left-to-right shunt (arrow) ASD, Atrial septal defect; LA, Left atrium; RA, Right atrium

The results were presented as the mean \pm the standard deviation (SD) for the continuous variables and absolute frequencies and percentages for the categorical variables. The $\chi^{2}$ tests were applied to compare the 2 groups in terms of the categorical variables. The continuous variables were compared using independent t-tests. The correlations between the continuous variables were assessed using the Pearson correlation coefficient. The nonparametric Kolmogorov-Smirnov test was performed to assess the normal distribution of the continuous variables, and the results showed that the normality assumption was not violated $(\mathrm{P}>0.05)$. All the statistical analyses were conducted using SPSS 18.0 for Windows (SPSS Inc, Chicago, IL, USA). P values of 0.05 or less were considered statistically significant.

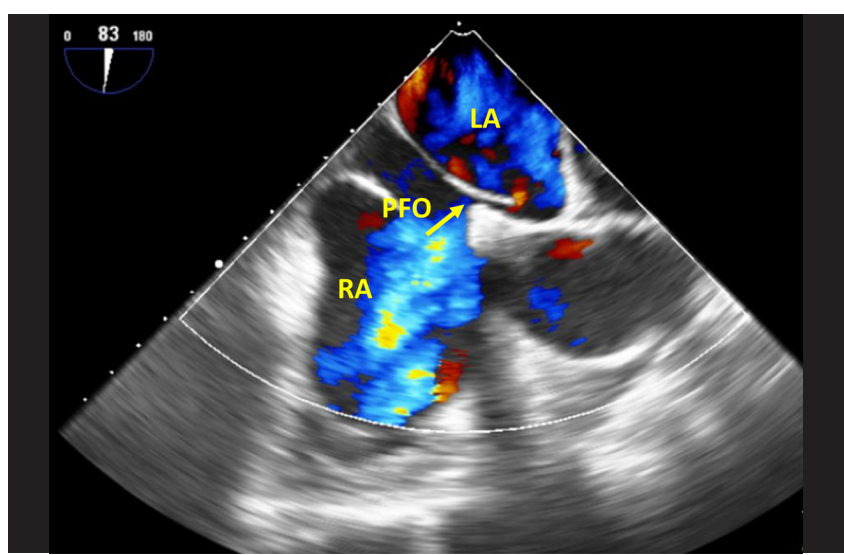

Figure 2. Transesophageal echocardiography image in the mid-esophageal view $\left(60-90^{\circ}\right)$, showing the PFO (arrow)

PFO, Patent foramen ovale; LA, Left atrium; RA, Right atrium; AO, Aorta

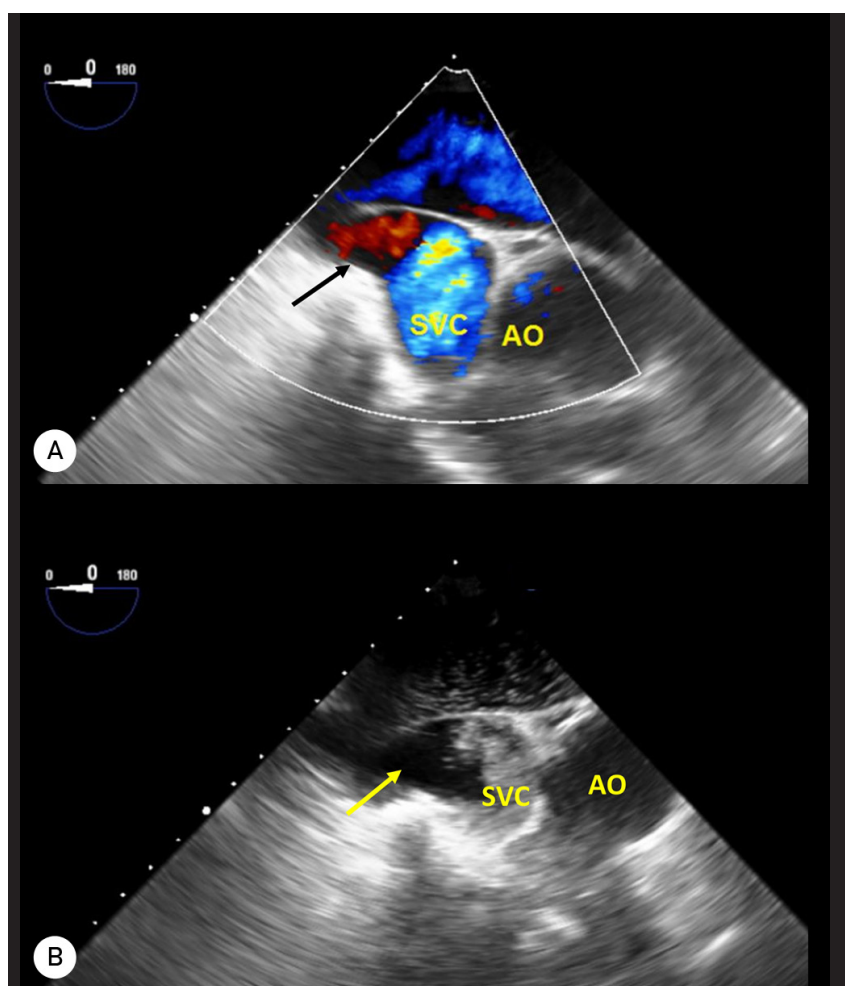

Figure 3. Transesophageal echocardiography images, showing anomalous pulmonary venous connections to the SVC:

A) upper-esophageal short-axis view $\left(0-30^{\circ}\right)$, showing the teardrop appearance of the SVC and the right upper pulmonary vein drainage into the SVC (black arrow) and B) upper-esophageal short-axis view $\left(0-30^{\circ}\right)$, contrast study with agitated saline, showing the pulmonary vein drainage into the SVC and negative contrast in the SVC (yellow arrow)

AO, Aorta; SVC, Superior vena cava 


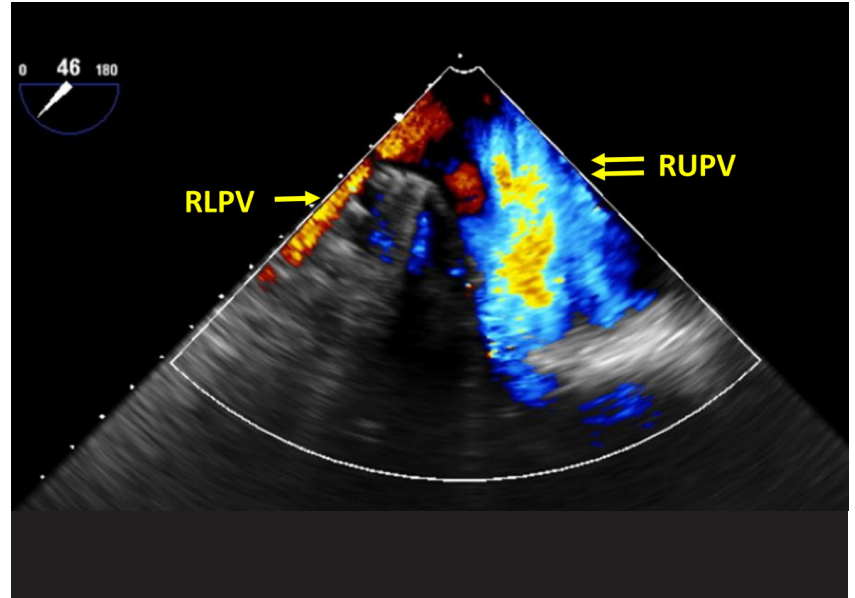

Figure 4. Transesophageal echocardiography image in the mid-esophageal view $\left(30-60^{\circ}\right)$, showing the right upper pulmonary vein drainage into the RA (double arrow) and the right lower pulmonary vein drainage into the LA (arrow)

RLPV, Right lower pulmonary vein; RUPV, Right upper pulmonary vein; RA, Right atrium; LA, Left atrium

\section{Results}

The case group was comprised of 187 patients with a definite superior type of SVASD diagnosed by TEE. Seven patients with inadequate data were excluded from the analysis. The control group consisted of 200 patients without congenital heart diseases that underwent TEE and TTE for other problems. The baseline demographic characteristics of the 2 groups are depicted and compared in Table 1. Of the 180 patients in the case group, 74 (41.1\%) were male and 106 (58.9\%) were female.

The frequency of female patients was significantly higher in the case group than in the control group $(\mathrm{P}=0.012)$ (Table 2). The comparisons of the echocardiographic parameters between the male and female patients with the SVASD are presented in Table 3. The patients with the SVASD were younger than those in the control group $(\mathrm{P}<0.001)$. The main objective of this study was to evaluate the presence of the PFO in patients with the SVASD. The presence of the PFO was significantly more frequent in the patients with the superior type of SVASD than in those without the condition $(\mathrm{P}<0.001)$ (Table 2). The prevalence of the PFO was $18.5 \%$ in the control group. The persistent left SVC was seen in $34(18.8 \%)$ patients with the SVASD and $1(0.5 \%)$ patient in the control group $(\mathrm{P}<0.001)$ (Table 2). The PAPVC was detected in 177 out of the 180 patients with the SVASD by TEE.

The correlations between defect size, right ventricular size, and Qp/Qs were significant in the patients with the SVASD. Increased defect size was associated with increased $\mathrm{Qp} / \mathrm{Qs}$ and right ventricular size $(\mathrm{P}<0.001 ; \mathrm{r}=0.377$ and
$\mathrm{P}<0.001 ; \mathrm{r}=0.386$, respectively). Increases in $\mathrm{Qp} / \mathrm{Qs}$ significantly increased right ventricular size $(\mathrm{P}<0.001 ; \mathrm{r}$ $=0.383)$. Delayed diagnosis of the SVASD significantly increased the pulmonary arterial pressure $(\mathrm{P}<0.001 ; \mathrm{r}=$ $0.311)$. The above mentioned parameters were not collinear $(\mathrm{R} 2<0.8)$. In the case group, the body surface area and right ventricular size were significantly higher in men than in women $(\mathrm{P}<0.001$ and $\mathrm{P}=0.001$, correspondingly $)$ (Table 2).

Table 1. Baseline demographic and echocardiographic characteristics of the case group*

\begin{tabular}{lcc}
\hline \multicolumn{1}{c}{ Variable } & Value \\
\hline Age $(\mathrm{y})$ & & $39.07 \pm 14.41(\mathrm{n}=169)$ \\
BSA (m2) & $1.70 \pm 0.19(\mathrm{n}=154)$ \\
RV size $(\mathrm{cm})$ & $4.40 \pm 0.68(\mathrm{n}=105)$ \\
TAPSE $(\mathrm{cm})$ & $23.42 \pm 5.33(\mathrm{n}=102)$ \\
RV S' $(\mathrm{cm} / \mathrm{s})$ & $13.58 \pm 3.35(\mathrm{n}=101)$ \\
Qp/Qs & $2.45 \pm 0.65(\mathrm{n}=83)$ \\
PAP (mmHg) & $44.94 \pm 19.05(\mathrm{n}=105)$ \\
ASD diameter $(\mathrm{cm})$ & $1.64 \pm 0.56(\mathrm{n}=100)$
\end{tabular}

"Data are presented as mean $\pm \mathrm{SD}$

n, Number of patients with available data; BSA, Body surface area; RV, Right ventricle; TAPSE, Tricuspid annular plane systolic excursion; S', Velocity of tricuspid annular systolic motion; PAP, Pulmonary arterial pressure; ASD, Atrial septal defect

Table 2. Comparisons of the baseline demographic and echocardiographic characteristics of the case and control groups ${ }^{*}$

\begin{tabular}{|c|c|c|c|}
\hline Variable & Case & Control & $\mathrm{P}$ \\
\hline Gender & & & 0.012 \\
\hline Female & $106(58.9)$ & $92(46.0)$ & \\
\hline Male & 74 (41.1) & $108(54.0)$ & \\
\hline
\end{tabular}

Age (y) $\quad 39.07 \pm 14.41(\mathrm{n}=169) \quad 51.01 \pm 15.80(\mathrm{n}=200) \quad<0.001$

$\operatorname{BSA}\left(\mathrm{m}^{2}\right) \quad 1.70 \pm 0.19(\mathrm{n}=154) \quad 1.74 \pm 0.18(\mathrm{n}=156) \quad 0.071$

PFO

$\begin{array}{ll}\text { Yes } & 81(45.0) \quad 37(18.5)\end{array}$

No $\quad 99(55.0) \quad 163(81.5)$

PLSVC

$<0.001$

$\begin{array}{ccc}\text { Yes } & 34(18.9) & 1(0.5) \\ \text { No } & 146(81.1) & 199(99.5)\end{array}$

${ }^{*}$ Data are presented as the mean $\pm \mathrm{SD}$ or $\mathrm{n}(\%)$.

$\mathrm{n}$, Number of patients with available data; PFO, Patent foramen ovale; BSA, Body surface area; PLSVC, Persistent left superior vena cava 
Table 3. Comparisons of the cardiac parameters between male and female patients in the case group*

\begin{tabular}{|c|c|c|c|}
\hline & Female & Male & $\mathrm{P}$ \\
\hline Age (y) & $\overline{39.88 \pm 14.93(n=101)}$ & $37.87 \pm 13.62(\mathrm{n}=68)$ & 0.375 \\
\hline BSA (m2) & $1.63 \pm 0.15(\mathrm{n}=89)$ & $1.81 \pm 0.19(\mathrm{n}=65)$ & $<0.001$ \\
\hline RV size $(\mathrm{cm})$ & $4.40 \pm 0.68(\mathrm{n}=105)$ & $4.74 \pm 0.65(\mathrm{n}=74)$ & 0.001 \\
\hline TAPSE (cm) & $23.42 \pm 5.33(\mathrm{n}=102)$ & $24.35 \pm 6.26(\mathrm{n}=73)$ & 0.291 \\
\hline $\mathrm{RV} \mathrm{SM}(\mathrm{cm} / \mathrm{s})$ & $13.58 \pm 3.35(\mathrm{n}=101)$ & $14.31 \pm 3.44(\mathrm{n}=72)$ & 0.169 \\
\hline PAP (mm Hg) & $44.94 \pm 19.05(\mathrm{n}=105)$ & $41.78 \pm 15.88(\mathrm{n}=73)$ & 0.246 \\
\hline Qp/Qs & $2.45 \pm 0.65(\mathrm{n}=83)$ & $2.59 \pm 0.75(\mathrm{n}=59)$ & 0.241 \\
\hline ASD diameter $(\mathrm{cm})$ & $1.64 \pm 0.56(\mathrm{n}=100)$ & $1.74 \pm 0.54(\mathrm{n}=65)$ & 0.266 \\
\hline PFO & & & 0.260 \\
\hline Yes & $44(41.5)$ & $37(50.0)$ & \\
\hline No & $62(58.5)$ & $37(50.0)$ & \\
\hline PAPVC & & & 0.999 \\
\hline Yes & $104(98.1)$ & $73(98.6)$ & \\
\hline No & $2(1.9)$ & $1(1.4)$ & \\
\hline PLSVC & & & 0.249 \\
\hline Yes & $23(21.7)$ & $11(14.9)$ & \\
\hline No & $83(78.3)$ & $63(85.1)$ & \\
\hline
\end{tabular}

${ }^{*}$ Data are presented as the mean \pm SD or $\mathrm{n}(\%)$.

n, Number of patients with available data; BSA, Body surface area; RV, Right ventricle; TAPSE, Tricuspid annular plane systolic excursion; S', Velocity of tricuspid annular systolic motion; PAP, Pulmonary arterial pressure; ASD, Atrial septal defect; PFO, Patent foramen ovale; PAPVC, Partially anomalous pulmonary venous connection; PLSVC, Persistent left superior vena cava

\section{Discussion}

The present study is the first investigation of its kind to investigate the presence of the PFO in patients with the superior type of SVASD (Figure 5). We noticed the existence of the PFO in most of our patients with the SVASD during TEE (which is performed routinely in patients with the SVASD). We, hence, retrospectively reviewed all the reports of the superior type of SVASD diagnosed by TEE in this center within the preceding 11 years to assess the existence of the PFO. The purpose of this study was to evaluate the presence of the PFO in patients with the SVASD and to highlight the importance of the preoperative detection of the PFO in patients with the SVASD. The ASD accounts for about $6 \%$ to $10 \%$ of all congenital heart diseases. With an incidence of 1 child per 1500 live births, the ASD is deemed the most common acyanotic congenital heart defect. While females constitute $65 \%$ to $75 \%$ of patients with the secundum ASD, there is no gender difference in patients with the sinus venosus ASD and the ostium primum ASD. ${ }^{9}$

The superior type of SVASD constitutes about $5 \%$ to $10 \%$ of all ASDs, and the SVC type is more common than the IVC type. The main factor in the SVASD diagnosis is the overriding of the SVC or the IVC on the intact muscular rim of the fossa ovalis, which makes the connection between the 2 atria. In the superior type of SVASD, there is a defect in the atrial wall between the SVC and the right pulmonary veins. As a result, the right pulmonary veins drain into the SVC and the right atrium. ${ }^{16-18}$

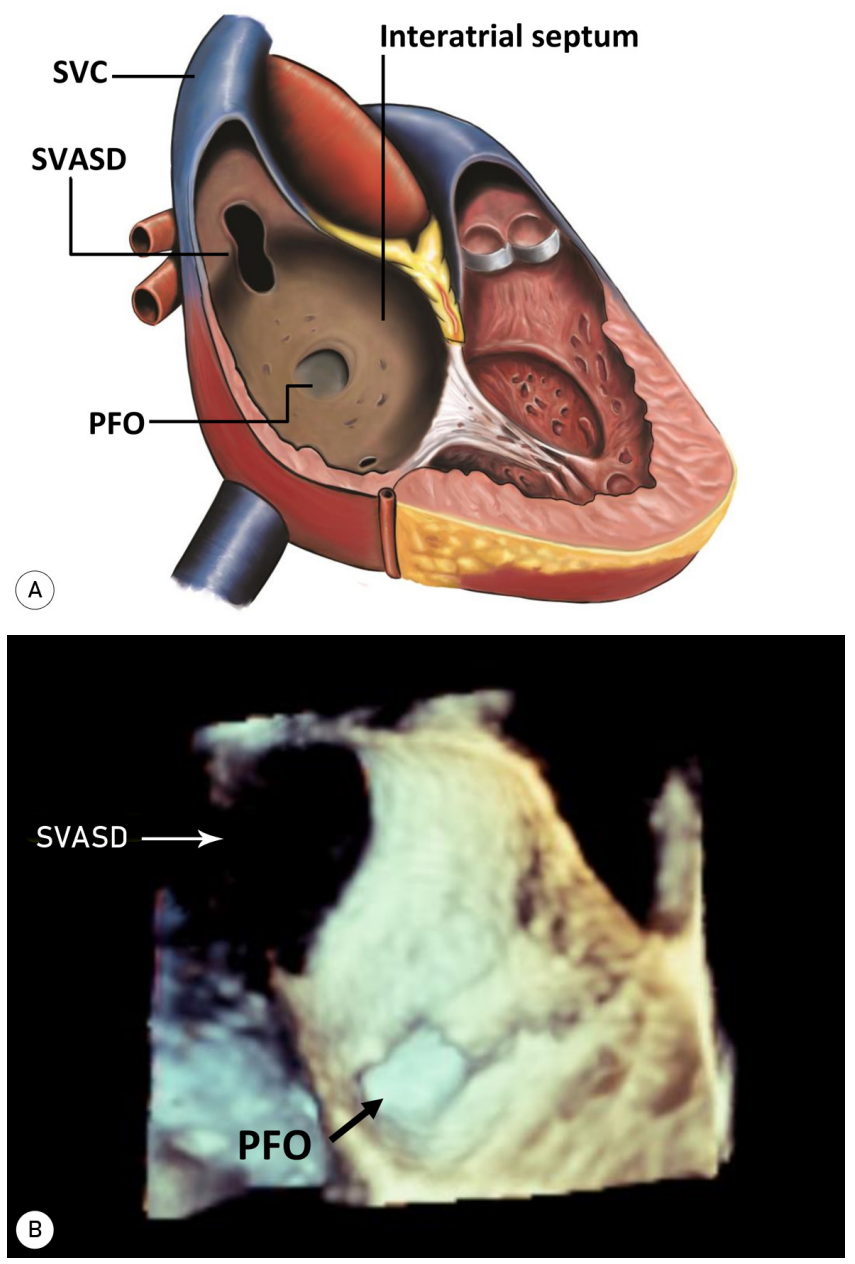

Figure 5. Relationship between the PFO and the ASD:

A) Schematic drawing of the anatomic relationship between the PFO and the SVC type SVASD; and B) 3D transesophageal echocardiography image in the mid-esophageal view $\left(90-110^{\circ}\right.$ ), showing the PFO (black arrow) and the superior type of SVASD (yellow arrow)

ASD, Atrial septal defect; SVC, Superior vena cava; PFO, Patent foramen ovale; SVASD, Sinus venosus atrial septal defect

The PFO, often considered to be a normal anatomical variant, is quite common and exists in more than $20 \%$ to $25 \%$ of adults. ${ }^{19}$ In the current study, the prevalence of the PFO in the control group (18.9\%) is relatively lower than that reported in previous studies. Autopsy studies have found the PFO in at least 1 out of every 4 patients. Younger adults with cryptogenic stroke are more likely to have the PFO than patients with other types of stroke. In adults, TEE is considered the gold standard for the diagnosis of the PFO. TTE with agitated saline contrast injection can be used as a 
sensitive method for the diagnosis of the PFO before TEE. ${ }^{4}$, ${ }^{20,21}$ For the detection of the PFO, agitated saline injection is performed with the Valsalva maneuver. Yamashita et $\mathrm{al}^{22}$ found the IVC compression as an effective method for the detection of the PFO when the patient cannot undergo the Valsalva maneuver. Moreover, coughing considerably increases the sensitivity of PFO detection. Injecting saline into the veins of the lower limbs increases the probability of saline passing through the PFO as the blood flows directly from the IVC into the fossa ovalis. ${ }^{23}$

The PAPVC occurs in about $80 \%$ to $90 \%$ of patients with the SVASD and $10 \%$ to $15 \%$ of cases with the primum ASD. However, only $10 \%$ of patients with ASD have the PAPVC. Echocardiography, multidetector computed tomography, and magnetic resonance imaging are noninvasive methods for the evaluation of the anatomy and abnormal communications of cardiac structures. Right heart catheterization provides information about the hemodynamic characteristics, blood oxygen saturation, and volumetric quantification of the ASD. ${ }^{24}$ Over time, the pulmonary artery flow increases due to left-to-right shunting, and the persistent exposure of the pulmonary vascular bed to high blood flow causes increased pulmonary vascular resistance and increased pulmonary artery pressure. ${ }^{25}$

Another finding that may be seen with the ASD is the atrial septal aneurysm, which is a redundant interatrial septum that bulges into the right or left atrium. The frequency of the atrial septal aneurysm is low in the general population. This type of aneurysm is associated with such cardiac abnormalities as the PFO, mitral valve prolapse, the ASD, and atrial arrhythmias. ${ }^{26-28}$

The persistent left SVC is the most common thoracic venous anomaly ${ }^{29,30}$ with an incidence rate of $0.3 \%$ to $0.5 \%$ in the general population and $3 \%$ to $10 \%$ in patients with congenital heart diseases. ${ }^{31,32}$ The condition is caused by a failure in the regression of the left anterior cardinal vein during cardiac development. The SVASD type affects about $4 \%$ to $11 \%$ of all ASDs associated with the persistent left SVC. ${ }^{29}$ In the present study, the persistent left SVC was more frequent in patients with the SVASD. Evaluating the abnormalities of the interatrial septum and anomalies concomitant with ASD requires multimodality assessments including TTE, TEE, intracranial ultrasound, and ultimately 3D imaging. ${ }^{19}$

\section{Conclusion}

The ASD is the most prevalent acyanotic congenital heart disease. The superior type of SVASD is a type of ASD generally associated with other congenital heart anomalies, particularly the PAPVC. Given that surgery is needed for SVASD repair, all the associated anomalies should be mentioned in the patient's echocardiography report. Due to the high rate of the association between the PAPVC and the SVASD, most physicians often look for the PAPVC when TEE is performed. Although surgeons fully examine the septum during surgery, sometimes only focusing on the SVASD and the PAPVC may mask the presence of the PFO.

This study was the first to highlight the coexistence of the PFO and the left persistent SVC in patients with the superior type of SVASD. The association between the PFO and the SVASD is unclear. However, physiological, genetic or fetal factors may play an important role in the association between the PFO and congenital heart anomalies such as the SVASD.

\section{Acknowledgments}

We would like to express our appreciation to Ms Zohreh Gholami for her assistance in this project. Many thanks are also to the nurses in the adult echocardiography ward. This study was approved and supported by Rajaie Cardiovascular Medical and Research Center.

\section{References}

1. Naqvi N, McCarthy KP, Ho SY. Anatomy of the atrial septum and interatrial communications. J Thorac Dis 2018;10(Suppl 24):S2837-S2847.

2. Windecker S, Wahl A, Nedeltchev K, Arnold M, Schwerzmann M, Seiler C, Mattle HP, Meier B. Comparison of medical treatment with percutaneous closure of patent foramen ovale in patients with cryptogenic stroke. J Am Coll Cardiol 2004;44:750-758.

3. Turc G, Calvet D, Guérin P, Sroussi M, Chatellier G, Mas JL; CLOSE Investigators. Closure, anticoagulation, or antiplatelet therapy for cryptogenic stroke with patent foramen ovale: systematic review of randomized trials, sequential meta-analysis, and new insights from the CLOSE study. J Am Heart Assoc 2018;7:e008356.

4. Kutty S, Sengupta PP, Khandheria BK. Patent foramen ovale: the known and the to be known. J Am Coll Cardiol 2012;59:16651671

5. Morton SU, Brodsky D. Fetal Physiology and the Transition to Extrauterine Life. Clin Perinatol 2016;43:395-407.

6. Chubb H, Whitaker J, Williams SE, Head CE, Chung NA, Wright MJ, O'Neill M. Pathophysiology and management of arrhythmias associated with atrial septal defect and patent foramen ovale. Arrhythm Electrophysiol Rev 2014;3:168-172.

7. Falanga G, Carerj S, Oreto G, Khandheria BK, Zito C. How to understand patent foramen ovale clinical significance: Part I. J Cardiovase Echogr 2014;24:114-121.

8. Lynch JJ, Schuchard GH, Gross CM, Wann LS. Prevalence of right-to-left atrial shunting in a healthy population: detection by Valsalva maneuver contrast echocardiography. Am J Cardiol 1984;53:1478-1480.

9. Webb G, Gatzoulis MA. Atrial septal defects in the adult: recent progress and overview. Circulation 2006;114:1645-1653.

10. Attenhofer Jost CH, Connolly HM, Danielson GK, Bailey KR, Schaff HV, Shen WK, Warnes CA, Seward JB, Puga FJ, Tajik AJ. Sinus venosus atrial septal defect: long-term postoperative outcome for 115 patients. Circulation 2005;112:1953-1958.

11. Pascoe RD, Oh JK, Warnes CA, Danielson GK, Tajik AJ, Seward JB. Diagnosis of sinus venosus atrial septal defect with 
transesophageal echocardiography. Circulation 1996;94:10491055 .

12. Donovan MS, Kassop D, Liotta RA, Hulten EA. Sinus venosus atrial septal defect as a cause of palpitations and dyspnea in an adult: a diagnostic imaging challenge. Case Rep Med 2015;2015:128462.

13. Kafka H, Mohiaddin RH. Cardiac MRI and pulmonary MR angiography of sinus venosus defect and partial anomalous pulmonary venous connection in cause of right undiagnosed ventricular enlargement. AJR Am J Roentgenol 2009;192:259266.

14. Kivistö $S$, Hänninen $H$, Holmström M. Partial anomalous pulmonary venous return and atrial septal defect in adult patients detected with 128 -slice multidetector computed tomography. J Cardiothorac Surg 2011;6:126.

15. Hoey ET, Lewis G, Yusuf S. Multidetector CT assessment of partial anomalous pulmonary venous return in association with sinus venosus type atrial septal defect. Quant Imaging Med Surg 2014;4:433-434.

16. Kessel-Schaefer A, Linka A, Pretre R, Buser P. Inferior sinus venosus defect associated with incomplete cor triatriatum dexter and patent foramen ovale. Eur J Echocardiogr 2006;7:239-242.

17. Sojak V, Sagat M, Balazova E, Siman J. Outcomes after surgical repair of sinus venosus atrial septal defect in children. Bratisl Lek Listy 2008;109:215-219.

18. al Zaghal AM, Li J, Anderson RH, Lincoln C, Shore D, Rigby ML. Anatomical criteria for the diagnosis of sinus venosus defects. Heart 1997;78:298-304.

19. Silvestry FE, Cohen MS, Armsby LB, Burkule NJ, Fleishman CE, Hijazi ZM, Lang RM, Rome JJ, Wang Y; American Society of Echocardiography; Society for Cardiac Angiography and Interventions. Guidelines for the echocardiographic assessment of atrial septal defect and patent foramen ovale: from the American Society of Echocardiography and Society for Cardiac Angiography and Interventions. J Am Soc Echocardiogr 2015;28:910-958.

20. Hubail Z, Lemler M, Ramaciotti C, Moore J, Ikemba C. Diagnosing a patent foramen ovale in children: is transesophageal echocardiography necessary? Stroke 2011;42:98-101.

21. González-Alujas T, Evangelista A, Santamarina E, Rubiera M, Gómez-Bosch Z, Rodríguez-Palomares JF, Avegliano G, Molina C, Alvarez-Sabín J, García-Dorado D. Diagnosis and quantification of patent foramen ovale. Which is the reference technique? Simultaneous study with transcranial Doppler, transthoracic and transesophageal echocardiography. Rev Esp Cardiol 2011;64:133-139.

22. Yamashita E, Murata T, Goto E, Fujiwara T, Sasaki T, Minami K, Nakamura K, Kumagai K, Naito S, Kario K, Oshima S. Inferior vena cava compression as a novel maneuver to detect patent foramen ovale: a transesophageal echocardiographic study. J Am Soc Echocardiogr 2017;30:292-299.

23. Homma S, Sacco RL. Patent foramen ovale and stroke. Circulation 2005;112:1063-1072.

24. Sharma RK, Houston BA, Lima JA, Cameron DE, Tedford RJ. Never too old for congenital heart disease: sinus venosus atrial septal defect with anomalous pulmonary venous return in an octogenarian. Pulm Circ 2015;5:587-589.

25. Anuwatworn A, Gedela M, Bendaly E, Prescott-Focht JA, Yee J, Clark R, Jonsson O. Sinus venosus atrial septal defect complicated by Eisenmenger syndrome and the role of vasodilator therapy. Case Rep Cardiol 2016:8164923.

26. Ghosh S, Ghosh AK, Ghosh SK. Patent foramen ovale and atrial septal aneurysm in cryptogenic stroke. Postgrad Med J 2007:83:173-177.

27. Mügge A, Daniel WG, Angermann C, Spes C, Khandheria BK, Kronzon I, Freedberg RS, Keren A, Denning K, Engberding R. Atrial septal aneurysm in adult patients. A multicenter study using transthoracic and transesophageal echocardiography. Circulation 1995;91:2785-2792.
28. Razaq M, Parihar RK, Saini G. Atrial septal aneurysm and stroke Ann Pediatr Cardiol 2012;5:98-99.

29. Disha B, Prakashini K, Shetty RK. Persistent left superior vena cava in association with sinus venosus defect type of atrial septal defect and partial pulmonary venous return on 64-MDCT. BMJ Case Rep 2014;2014:bcr2013202999.

30. Sahay S, Krasuski RA, Tonelli AR. Partial anomalous pulmonary venous connection and pulmonary arterial hypertension. Respirology 2012;17:957-963.

31. Sahin T, Kilic T, Celikyurt U, Bildirici U, Ural D. Persistent left superior vena cava and partial anomalous pulmonary venous return in an old asymptomatic female patient. Cardiol Res Pract 2009;2009:152164.

32. Kurtoglu E, Cakin O, Akcay S, Akturk E, Korkmaz H. Persistent left superior vena cava draining into the coronary sinus: a case report. Cardiol Res 2011;2:249-252. 